\title{
Article \\ Risk Assessment of Riverine Terraces: The Case of the Chenyulan River Watershed in Nantou County, Taiwan
}

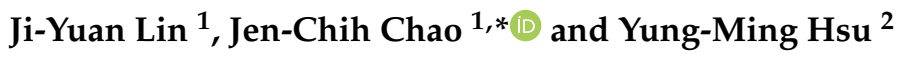 \\ 1 Department of Landscape and Urban Design, Chaoyang University of Technology, Taichung 413310, Taiwan; \\ jylin@cyut.edu.tw \\ 2 Department of Civil \& Construction Engineering, Chaoyang University of Technology, \\ Taichung 413310, Taiwan; s9911625@cyut.edu.tw \\ * Correspondence: jenchihchao@gmail.com; Tel.: +866-423323000 (ext. 7668)
}

Citation: Lin, J.-Y.; Chao, J.-C.; Hsu, Y.-M. Risk Assessment of Riverine Terraces: The Case of the Chenyulan River Watershed in Nantou County, Taiwan. Appl. Sci. 2022, 12, 1375. https://doi.org/10.3390/ app12031375

Academic Editors: Andrea Chiozzi, Elena Benvenuti and Željana Nikolić

Received: 16 November 2021

Accepted: 19 January 2022

Published: 27 January 2022

Publisher's Note: MDPI stays neutral with regard to jurisdictional claims in published maps and institutional affiliations.

Copyright: (C) 2022 by the authors. Licensee MDPI, Basel, Switzerland. This article is an open access article distributed under the terms and conditions of the Creative Commons Attribution (CC BY) license (https:// creativecommons.org/licenses/by/ $4.0 /)$.

\begin{abstract}
The purpose of this study is to establish a method of hazard assessment for the river terraces along the Chenyulan River and use 40 of them as protected objects. Using a geographic information system, the researchers extracted nine parameters for such terraces. These are length to attack shore, distance away from fault, distance from river channel, number of creeks and streams with possibility of debris flows, height above stream level, average slope degree, geology, number of erosion ditches, and distance from landslide area behind. Next, the weightings identified by analytic hierarchy process analysis were used as the basis for grading the various factors affecting river terraces. Hazard assessment for the river terraces then proceeded via totaling of the potential trends of the various factors and the protected objects, as well as comparison of historical disaster conditions and satellite images. The results showed that there were 8 high-risk river terraces, 14 medium-high-risk river terraces, 14 medium-low-risk river terraces and 4 low-risk river terraces. The evaluation of the current conditions of the settlement environment through parameter weighting has a certain accuracy and reference value in reducing the disaster impact of the riverine terrace settlement.
\end{abstract}

Keywords: geographic information system; hazard assessment; river terraces; risk assessment

\section{Introduction}

Taiwan is located at the junction of the Eurasian continental plate and the Philippine Sea plate. Formed through the Penglai orogeny, the Nanao orogeny and crustal changes, it is a mountainous terrain with flat land accounting for only $25 \%$ of its total area. Due to population growth and rapid industrial and commercial development in Taiwan in recent years, the use of flat land has become saturated, and development of hillside areas, especially river terraces, has become common. The existence of river terraces indicates frequent geological changes, high erosion rates, abundant sources of silt, and strong river scour [1], but their formation is also affected to some extent by climate change and human activities [2]. As Taiwan is surrounded by the sea on all sides, it receives abundant rainfall throughout the year, about $2500 \mathrm{~mm}$, more than two and a half times the world annual average of $970 \mathrm{~mm}$. During the rainy season (from 1 May to 30 November each year), the region is prone to typhoons, each of which tends to increase the intensity of rainfall within a short period of time, and this can result in landslides and mudslides in mountainous areas, as well as rapid rises in the water levels in rivers, which often results in flooding and the erosion and collapse of riverbanks. To prevent loss of life, residents of river terraces have to evacuate when typhoons occur. On 7 August 2009, when Taiwan was struck by a moderate-strength typhoon, Morakot, heavy rainfall led to a series of disasters in southern Taiwan. Due to the collapse of Xiandu (Xianto) Mountain, Xiaolin Village was destroyed, and a short-term barrier lake that was formed endangered the lives and property of residents downstream. 
Due to undercutting and erosion by rivers, river terraces remain above the water surface during normal floods and are distributed in steps on the slopes of the river valleys [3]. Chang and Shi defined river terraces as land along rivers, consisting of terraces and cliffs [4]. The terraces' surfaces were the riverbed or floodplain surfaces in a former period, while the cliffs below them, facing the valley axis, were formed by both down erosion and lateral erosion [2]. The terraces of Xiaolin Village were formed by ancient and recent landslides. Their geology is extremely unstable, and the village was destroyed largely due to its location on dangerous low-lying ones. According to our survey, among the 144 mountain settlements and aboriginal tribal villages in southern Taiwan, 92 are located on river terraces, similar to the situation of Xiaolin. Therefore, the hazard and risk assessment of river terraces demand special attention to avoid similar disasters.

Various explorations of the topographic evolution of river terraces and the reasons they are formed in different regions have been conducted [5-8]. Scholars have also investigated the risks to river-terrace settlements posed by rainfall-induced landslides, based on historical data regarding the potential risk range of debris flows and the areas where landslides occur [9-11]. The Chenyulan River, in particular, has been the subject of multiple studies focused on collapses' potential indicators and locations [12-14], due to the multiple disasters that have struck the terraces of its lower reaches. However, due in part to strong variation in the reasons for the formation of river terraces and the hazards they face, residents of river-terrace settlements tend to have low awareness of disaster risks and are thus unable to effectively mitigate them. The people who live in settlements on the river terraces in Chenyulan today could face disaster at any time. Therefore, levels of danger to such terraces are estimated by risk assessment, so that when a typhoon is about to strike Taiwan, local residents can be quickly moved to safe places and disaster-relief facilities.

This study focuses on factors that may harm river terraces, derived from special questionnaires to establish index weights, and uses a geographic information system (GIS) overlap to allocate these factors to particular river terraces. Then, the scores of these potential factors and preservation factors are summed to estimate the terraces' risk, and establish a risk map of the area, with the wider aim of disaster prevention and reduction in disaster losses. This study uses the analytical features of AHP multilevel evaluation to decompose the elements of the river terraces' environment and construct a model of potential factors of the river terraces. Using the GIS data and AHP model, a matrix of judgement is established based on the corresponding criteria to derive the corresponding element weights, and a spatial analysis of the river terraces' hazard trend map is used to provide a solution to reduce the impact caused by the disaster.

\section{Study Area}

Li's survey of the Chenyulan River noted that its inland river terraces, alluvial fans and landslides were highly developed, and that there were 46 fan-shaped terraces and alluvial fans. The large number of these features implies rapid geological change [1].

According to the Bureau of Soil and Water Conservation, part of Taiwan's Council of Agriculture, there are more than 1700 potential soil and rock flows [15]. Within our study area, as shown in Figure 1, there are 49 such potential flows.

\section{Literature Review}

The potential hazard factors affecting river terraces can be summarized into three latent-sensing categories. The first, in front of the terrace, comprises four factors: attack shore, distance from fault, distance from river, and potential stream-impact quantity. The second, of the river terrace itself, consists of three factors: minimum ratio, average slope and geology. Additionally, the third, behind the river terrace, includes two factors: number of erosion ditches and number of collapses from the rear. Each category is analyzed in the following sections. 


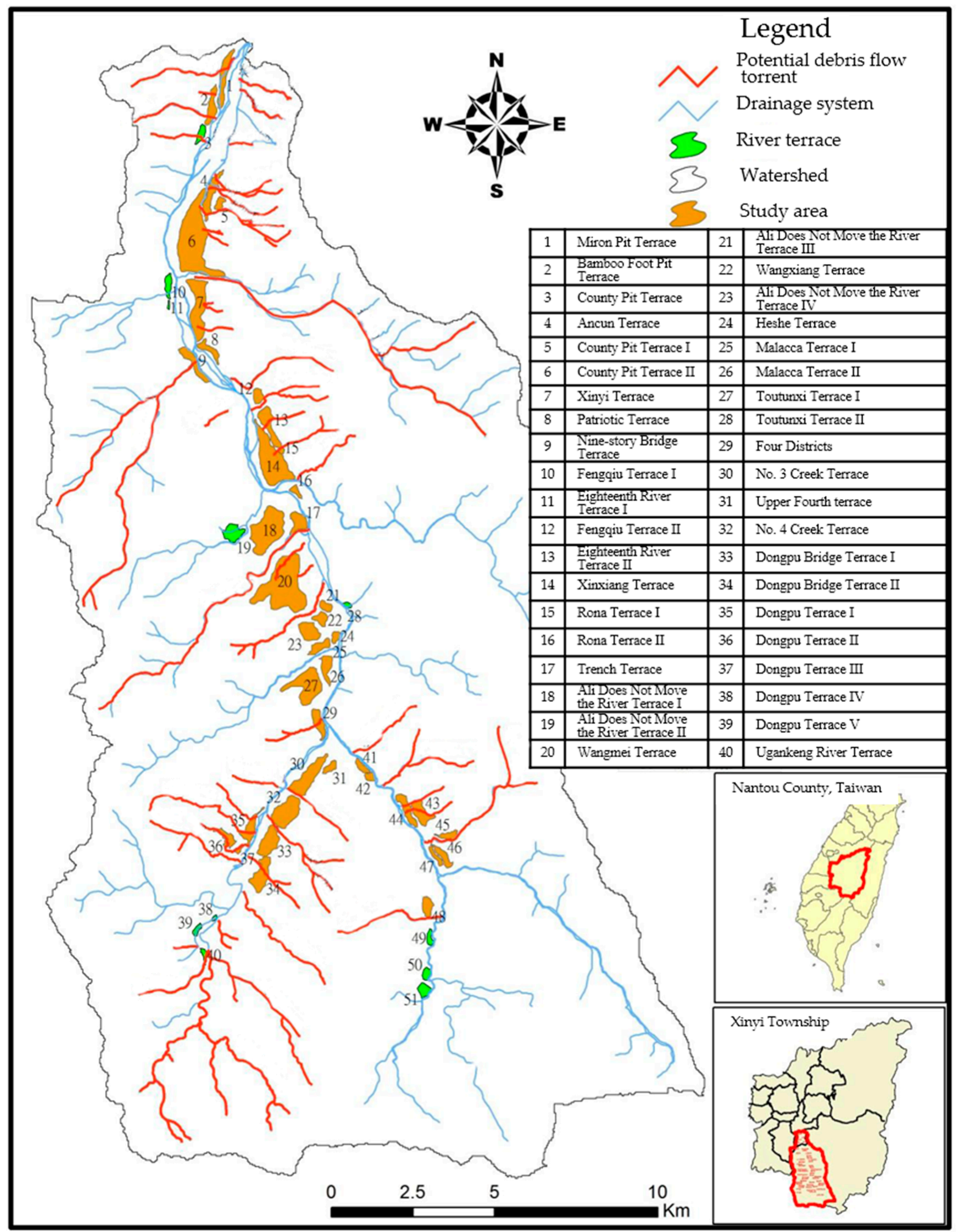

Figure 1. Study area. 


\subsection{The Front of the Terrace}

\subsubsection{The Attack Shore}

Lin et al. showed that riverbank erosion mainly occurs at the bends in the river courses and tends to be most severe at the outer edges of such bends, called the attack shore (or cutting slope) [16]. The riverbank located on the attack shore has been eroded by the river for a long time, and the soil and rocks detached by such erosion are constantly being carried away by the river water, causing the toe to be gradually emptied; over time, this makes the riverbank steeper until it collapses. Roads and building foundations on the top are then damaged, or in some cases completely destroyed, due to loss of support. Lin et al. also noted that the movement of sandbars is mainly affected by five factors, i.e., the presence or absence of bends in rivers, the degree of such bends' curvature (known as meander), the presence or absence of confluent lateral structures, the way the river is scrubbed, and the supply of soil and sand [17]. Generally, convex-bank sandbars in curved sections of a river are more developed, and water flows mostly to the concave bank-i.e., the attacking shore-to erode it. Su concluded that, when the river flows through the attacking shore, flow velocity increases, and the centrifugal vortex water is formed there, washing it and transporting soil and sand to the convex bank [18].

\subsubsection{Distance from Fault}

Being located at the junction of the Eurasian continental plate and the Philippine Sea plate, Taiwan experiences frequent seismic activity. According to data collected by its Central Meteorological Bureau from 1991 to 2006, there are about 18,500 earthquakes in Taiwan each year, of which around 1000 are felt earthquakes. Major earthquakes often result in surface ruptures, rock folds and new faults. At present, scientists are unable to determine whether such faults cause earthquakes or vice versa, but their locations are identified in areas where seismic energy is strong [19]. Geological conditions in such areas are very fragmented due not only to the presence of fault gouges but also to broken zones near them and changes in the Earth's crust. The physical properties of the filler between the discontinuous surfaces of fault gouge or broken zone are usually poor, as is the degree of cementation, and this often causes engineering problems [16]. Lin observed that the rock mass on both sides of the Chenyulan fault is relatively broken, and weathered slate and metamorphic sandstone there, respectively provide fine-grained and coarse-grained material for earth-rock flows. The effects of faulting and river erosion also contribute to such flows [20]. The slopes of the terrain along both sides of the river are relatively steep, so the original weathered-soil layer collapsed due to by heavy rain and formed debris flows. During these flows, the rock plate was broken, and the broken pieces in the rock mass were drawn into them.

\subsubsection{Distance from River}

Wang's study of the Shaolai River concluded that the collapse percentages of susceptibility increased with proximity to the river's course. Specifically, the percentage of collapses within $200 \mathrm{~m}$ from the river channel was $42.7 \%$; between $200 \mathrm{~m}$ and $400 \mathrm{~m}, 26.6 \%$; between $400 \mathrm{~m}$ and $600 \mathrm{~m}$, accounted for $19.4 \%$ [21]. Beyond $1600 \mathrm{~m}$ from the river channel, there were no collapses at all. Therefore, it can be inferred that large increases in the collapsed areas of adjacent rivers may be related to heavy typhoon rain causing water levels to surge, which in turn eroded the slope foot of the Shaolai River and accelerated the collapse of the riverbank [22]. In short, a closer distance to the river entails a higher level of risk. It is also a principle of hydrology that when the slope is closer to the river, it is nearer to groundwater; thus, water seeping into the ground will cause seepage pressure in the slope. If the soil structure is highly permeable, this process will greatly increase the probability that the stability of the slope will be negatively affected [23]. As Chang et al. observed, distance from the river channel determines flood impact [24]. The smoothness of a river channel determines its flood-discharge capacity, and the reclamation-area ratio of a reclaimed lake determines the flood-regulation capacity of the lake in the protection zone. 


\subsubsection{Potential Stream-Impact Quantity}

According to a comprehensive assessment by Taiwan's Bureau of Soil and Water Conservation [15], natural streams or pits are likely to cause debris-flow disasters, though this likelihood is affected by local conditions including the presence or absence of protected objects. The Bureau uses two main criteria for judging the probable impact of potential debris flows. The first is that the slope of the stream bed is greater than 10 degrees, and that the catchment area above this point is greater than three hectares. The second is that, at the downstream exit or overflow point of the stream, there are more than three households or important bridges or roads that need to be protected. Assessment should be divided into four levels-"high", "medium", "low", and "continuous observation"—-based on the characteristics of the site.

\subsection{The River Terrace Itself}

\subsubsection{Minimum Ratio}

Specific height is defined as the height of the riverbank relative to that of the riverbed surface. Yoshiro divided Taiwan's terrain into eight types; from high to low, these were Highest Peneplain (HP), Old Piedmont (OP), Elevated Highland (EH), Young Piedmont (YP), Lateritic Highland (LH), Lateritic Terrace (LT), Fluvial Terrace (FT), and Fluvial Plain (FP) [25]. Through this perspective, the topographic evolution of the Taiwan River Valley can be explored. Lin subsequently provided a general description of the topographical features of Taiwan's important river systems, along with more detailed descriptions of the topographical categories defined by Tomita $[25,26]$.

\subsubsection{Average Slope}

According to statistics from the Bureau of Soil and Water Conservation, the most frequent damage from debris flows occurs on Taiwan's mountain slopes above 30 degrees, and especially at 40 degrees or more, while the least damage is suffered where slopes are 15 degrees or less [15]. This is because steep slopes provide greater driving force and also reduce slope resistance, making them conducive not only to the development of shallow landslides but also to the fluidization of landslides and the formation of sloping debris flows [27]. Cheng used GIS and a conditional-probability method to analyze four factors-bare land, eroded gullies, slope, and lithology — and established that, among them, slope had the greatest influence [28]. Kao showed that unstable Index method achieved good accuracy in predicting slope collapses, with $92 \%$ of actual collapsed land falling within the areas it identified as being at medium or high risk [29,30]. Liulater used a neural network-like sensitivity analysis to establish that the most important factors in this type of damage were rainfall, slope, slope type, elevation, lithology, fault, slope direction, roads, folds, and erosion gullies [30]. After controlling for rainfall, however, the greatest influence was slope, irrespective of whether Kao's or Liu's analysis method was applied.

\subsubsection{Geology}

The right bank of the main channel of the Chenyulan River consists of Paleogene submetamorphic rock strata, with interbedded argillite, slate, meta sandstone and quartzite, among other types of rock; on the left bank are Miocene sedimentary rock strata, with interbedded sandstone, shale and sand shale. Other strata include platform accumulation, four-sided sandstone layers, and hsichun, shihti, alluvial, nanchung, kueichoulin and kankou formations [31]. The wider area is dominated by thick-bedded sandstone, shale (argillite), and sandstone and shale formed together. When thick-bedded sandstone is subjected to tectonic stress, the rock mass is often cut into large blocks because it is thick and strong, but the density of the fractured surface is low. This type of rock is also relatively easy to weather. When the degree of weathering is slight, shale often forms smaller cuttings; when the degree of weathering is severe, a weathered soil layer forms. Due to the sharp difference in water permeability and resistance between sand and shale interbeds, the interface between them is often a stratum-slip surface, and the exposed area of interbeds 
often forms a single-sided mountain topography [32]. Chang and Lin investigated the Chenyulan River after Typhoon Huber and found that the contact between the upper mountain belt and the submetamorphic belt of Taiwan's geological structure was a fault. That is to say, near the Chenyulan River, the rock mass is abnormally broken, and a considerable amount of broken rock and soil accumulates on the surfaces of slopes and in the river itself, which may cause disasters [33].

\subsection{Rear of the Terrace}

\subsubsection{Number of Erosion Ditches}

Chang showed that erosion ditches are mainly caused by rain, surface runoff and wind, which causes the original soil to loosen or move; this process removes fine particles, and the resultant slope appears to be grooved [34]. Taiwan's Water Resources Agency, MOEA, on the other hand, defined an erosion ditch as a slender, linear drainage route from the top of a slope to its foot, usually caused by incision and erosion by concentrated runoff on the slope's surface. At the same time, the ditch wall is emptied and collapses, forming an obvious drainage pipe [35]. Chang suggested that the degree of slope erosion is a dynamic topographic effect on slope and is judged by the degree of contour curvature on a topographic contour map, supplemented by field surveys. Such curvature can also be used to determine the grade of a slope-erosion gully, i.e., a trough-shaped depression formed by the removal of vegetation by runoff on a hillside, excluding stream beds [36]. Hung noted that the debris-flow disasters caused by Typhoon Huber in the Chenyulan River Basin mainly occurred in the large erosion ditches (some of which are large enough to be named "Stream") and the flat reclaimed land of the community at the intersection and Provincial Highway 21 [37].

\subsubsection{Number of Collapses from the Rear}

When the combination of hydrological and geological conditions exceeds its damage threshold, a hillside will collapse. Hydrological conditions include rainfall intensity, rainfall delay, the soil's water content, pore water pressure, etc. Geological conditions include soil cohesion, anti-friction angle, soil slope, surface vegetation and whether there has been a recent earthquake or not. Tang conducted simulations of the Xiaolin Village disaster using PFC 3D. Their preliminary results show that just $60 \mathrm{~s}$ after the landslide was triggered, some of the houses in the village may have been covered by falling rocks or pushed to the opposite bank of the Qishan River [38]. Certainly, at its maximum sliding speed of $50 \mathrm{~m}$ per second, the kinetic energy of soil and rock is sufficient to cross the river entirely at this point, and a barrier lake was formed by this process in this vicinity. Ji investigated landslides in Caoling over a period from 1862 to 1999 and identified five large-scale ones linked to earthquakes or heavy rain. The landslides directly or indirectly caused disaster to the Caolingtan dyke breach, and a total of 170 people were killed and injured. Additionally, during the "921" earthquake of 1999, Caoling Mountain collapsed rapidly, its soil and rock moving up to $4 \mathrm{~km}$, and the impact area of the collapse was nearly 500 hectares. Such cases of large-scale rock mass sliding are extremely rare, in Taiwan or anywhere else [39].

\subsection{Preservation-Factor Assessment}

Preservation factors include households, schools, hostels, public buildings (if residential), roads, bridges, farmland, orchards and other such sites. The Bureau of Soil and Water Conservation noted that the streams' debris-flow potential should be evaluated and prioritized according to the formula (natural potential factor affecting the risk level of debris flow $\times 50 \%)+($ preservation hazard factor $\times 50 \%$ ) [15]. The individual scores for the following three factors were added together to obtain the hazard degree score for each preservation object. (1) Building factor: The more buildings there are, the more people live in them, so the damage score is higher. (2) Traffic factor: Damage to the bridge is more harmful to the traffic, so a higher score is given. (3) Effective factors of on-site remediation: After many disasters, there have been many remediation facilities for potential debris flows. 
If the remediation facilities are effective, damage to preservation objects by such flows can be reduced.

\section{Methods}

This study used Li's Chenyulan River terrace map data, modified to reflect the current shape of river terraces there, and purposively selected 40 potential river terraces for further analysis [1]. An analytic hierarchy process was used to analyze the strength of the mutual influences of the various elements, as well as of the high-level elements on the low-level elements; the levels of risk to each focal river terrace were derived through weighting the latent perception factors [40].

\subsection{Questionnaire Design}

In this study, following the methodology laid out by the Bureau of Soil and Water Conservation, the priority-order score of the potential unearthed rock flows was calculated according to the formula set forth in Section 2.4 above. Therefore, the risk-scoring method for the river terraces in this study equals (the potential factor of river terraces $\times 50 \%$ ) + (the preservation hazard factor of the river terraces $\times 50 \%$ ) [15]. The questionnaire design can be divided into the two hierarchical-structure diagrams-one for latent factors and the other for preservation factors, shown in Figures 2 and 3.

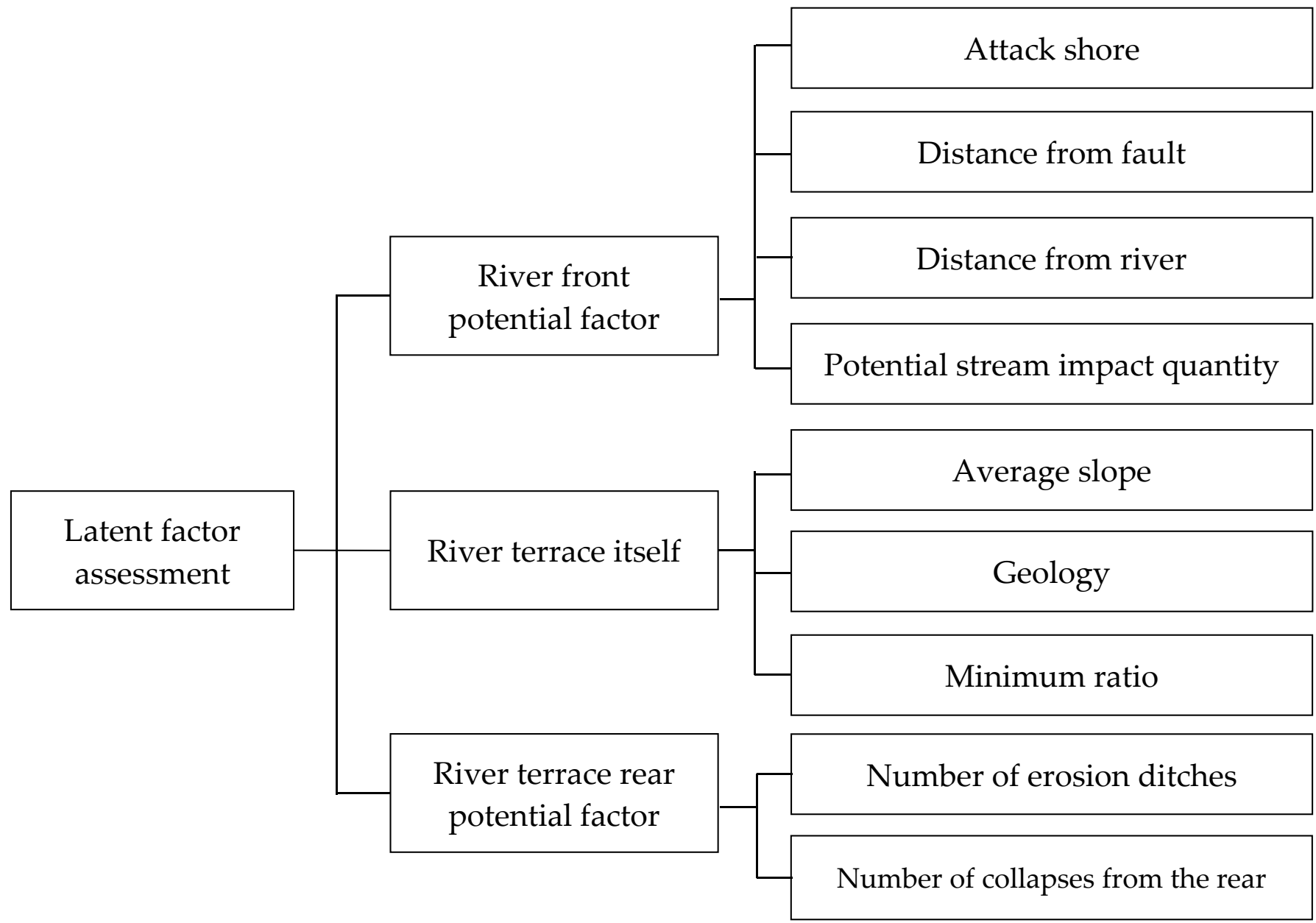

Figure 2. Evaluation conditions of latent factors and hierarchy of related factors. 


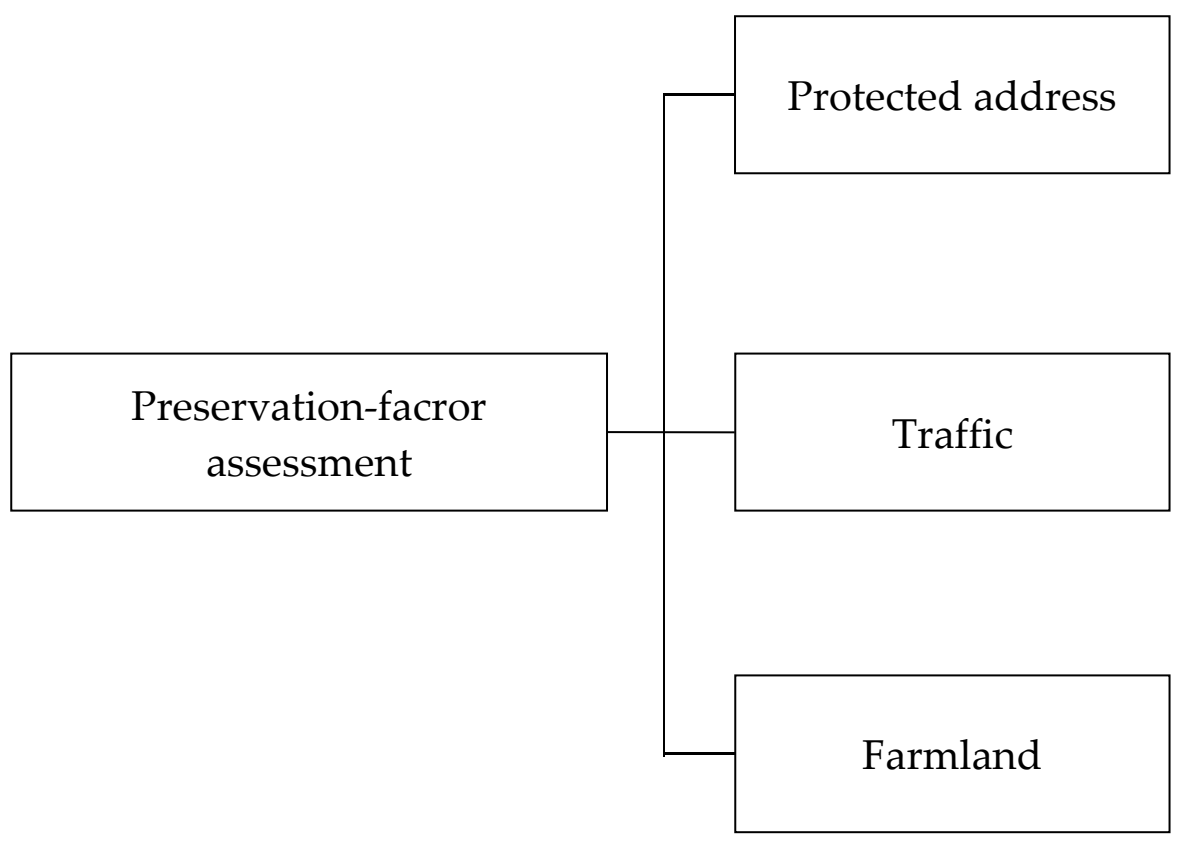

Figure 3. Evaluation conditions of preservation factors and hierarchy of related factors.

\subsection{Questionnaire Survey Subjects}

The participants in the questionnaire survey were mainly professors from the fields of land, water conservancy, soil and water conservation, geology, and environment and disaster prevention, employed by National Taiwan University, Chung Hsing University, Kaohsiung University, Tamkang University, Hua Fan University, Pingtung University of Science and Technology, and Chaoyang University of Science and Technology.

\subsection{Statistical Results of Questionnaire Recovery}

A total of 23 questionnaires were sent out and 17 were returned, resulting in a response of $79.9 \%$. After eliminating five questionnaires due to repeated answers or omitted, unanswered items, which led them to have a consistency index (C.I.) and a consistency ratio (C.R.) greater than $0.1,12$ valid questionnaires remained for analysis. The C.R. value achieved a margin $<0.1$, indicating a strong degree of consistency among the pairwise comparisons, and proved it did not require a statistically significant sample size [40]. Shrestha et al. pointed out that AHP is usually used to survey people who have knowledge about the topic under investigation and a large sample size is not needed [41].

\section{Results}

Based on AHP principles, the scale indicates the level of relative importance from equal, moderate, strong, very strong to extreme level by $1,3,5,7$, and 9 , respectively. The intermediate values between two adjacent comparisons are denoted by $2,4,6$, and 8 . The diagonal of the matrix of the comparison is equal to 1 , since each criterion is compared to itself. When the number of alternatives is $n$, a total of $n(n-1) / 2$ comparisons are made [40]. As shown in Table 1, our expert respondents' ranking of our three categories of latent-sensing factors was in front of river terrace $(0.352)>$ river terrace itself $(0.342)>$ behind river terrace (0.306).

In the experts' evaluation of the preservation factors of river terraces, as shown in Table 2, the ranking was households (0.599) > traffic (0.292) > farmland (0.109). 
Table 1. Evaluation results, river terraces' latent-sensing factors.

\begin{tabular}{|c|c|c|c|c|c|}
\hline Level & \multicolumn{2}{|c|}{ Evaluation Project } & Inter-Level Weight & Overall Weight & Rank \\
\hline \multirow[t]{2}{*}{ Level one } & \multicolumn{2}{|c|}{ Latent factor assessment } & 1.000 & 1.000 & \\
\hline & & In front of river terrace & 0.352 & 0.352 & \\
\hline \multirow{3}{*}{ Level two } & \multirow{3}{*}{ Latent factor assessment } & River terrace itself & 0.342 & 0.342 & \\
\hline & & Behind river terrace & 0.306 & 0.306 & \\
\hline & & Attack shore & 0.379 & 0.133 & 3 \\
\hline \multirow{4}{*}{ Level three } & \multirow{4}{*}{ In front of river terrace } & Distance from fault & 0.096 & 0.034 & 9 \\
\hline & & Distance from river & 0.288 & 0.101 & 7 \\
\hline & & Potential impact of debris-flow quantity & 0.237 & 0.083 & 8 \\
\hline & & Average slope & 0.321 & 0.110 & 6 \\
\hline \multirow{2}{*}{ Level three } & \multirow{2}{*}{ River terrace itself } & Geology & 0.354 & 0.121 & 4 \\
\hline & & Minimum ratio & 0.325 & 0.111 & 5 \\
\hline \multirow{2}{*}{ Level three } & \multirow{2}{*}{ Behind river terrace } & Number of erosion ditches & 0.563 & 0.172 & 1 \\
\hline & & Distance from the collapse & 0.438 & 0.134 & 2 \\
\hline
\end{tabular}

Table 2. Evaluation results of river terraces' preservation factors.

\begin{tabular}{ccccc}
\hline Level & Evaluation Project & Inter-Level Weight & Overall Weight \\
\hline Level one & Preservation factor assessment & 1.000 & 1.000 \\
& & Protected address & 0.599 & 0.599 \\
Level two & Preservation factor assessment & Traffic & 0.292 & 0.292 \\
& & Farmland & 0.109 & 0.109 \\
\hline
\end{tabular}

\subsection{Distribution Method}

Due to the large gaps between the various factors, to avoid extreme values, we first used statistical methods to find the average value and standard deviation of each factor and set reasonable parameter ranges $X_{\max }$ and $X_{\min }$. If a parameter was greater than $X_{\max }$, $X_{\max }$ was used, and if one was less than $X_{\max }, X_{\min }$ was used. Then, an interval mapping method was conducted with AHP weightings to determine the score for each factor. In this study, the maximum and minimum range (0.1-1) of the interval mapping method was multiplied by the overall weight of each factor in the AHP to obtain the maximum and minimum range values.

\subsection{Factor-by-Factor Allocation}

First, we assumed that each factor was normally distributed, and its average value and standard deviation were ascertained, using one standard deviation to determine its reduction range. In this way, the extreme value of each parameter had less influence when calculating the weight, as shown in Table 3.

Table 3. Average value and standard deviation of each factor.

\begin{tabular}{|c|c|c|c|}
\hline Factors & Average Value & Standard Deviation & $X_{\max }-X_{\min }$ \\
\hline Minimum height ratio (m) & 58.6 & 64.4 & $0-123$ \\
\hline Attack shore length (m) & 213.9 & 375.1 & $0-589$ \\
\hline Distance from river $(\mathrm{m})$ & 182.2 & 202.3 & $0-384.4$ \\
\hline Average slope (degrees) & 10.4 & 4.5 & $5.9-14.8$ \\
\hline Distance from fault (m) & 388.6 & 455.2 & $0-843.7$ \\
\hline Number of potential streams affected & 2.2 & 2.1 & $1.1-5.3$ \\
\hline Number of erosion ditches & 3.2 & 2.5 & $0.7-5.6$ \\
\hline Distance from the collapse (m) & 654.2 & 388.7 & $285.5-1022.9$ \\
\hline Protected address & 91.1 & 130.1 & $0-221.1$ \\
\hline
\end{tabular}

According to Juang et al., to improve the learning rate and accuracy of a similar neural network, the inconsistency of the difference between the numerical ranges of the parameters should be calculated, as before analysis, the input parameters must be normalized to avoid 
the problem of temporary instability of the network and difficulty in convergence [42]. Accordingly, this study utilized a modified version of the interval-mapping method in Juang et al.'s normalization formula, and the maximum and minimum values obtained were between 0.1 and 1 .

$$
\text { "X" _"norm" " =" ("X+a")" } / b^{\prime \prime} X_{\text {norm }}=(X+a) / b
$$

Among them:

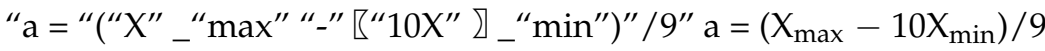

$$
\begin{aligned}
& \mathrm{b}=\left(\mathrm{X}_{\max }-\mathrm{X}_{\min }\right) / 0.9
\end{aligned}
$$

In the above three formulae, $X_{\text {norm }}$ is the normalized value; $X$ is the actual input parameter value; $X_{\max }$ is the maximum actual input parameter; $X_{\min }$ is the minimum actual input parameter.

For ease of calculation, a full score was held to be 100 points. In this study, the maximum and minimum range of the interval mapping method (0.1-1) is multiplied by the overall AHP weight of each factor and then multiplied by 100 to obtain the factors' respective maximum and minimum ratio ranges, as shown in Table 4 . Substituting the data of each factor into Equation (1), the calculation formula of each factor can be calculated, and the factor weight of each river terrace calculated.

Table 4. Weight distribution of each factor.

\begin{tabular}{cccc}
\hline \multicolumn{2}{c}{ Factors } & Maximum Weighting & Minimum Weighting \\
\hline & Minimum height ratio (m) & 11.1 & 1.11 \\
& Attack shore length (m) & 13.3 & 1.33 \\
& Distance from river (m) & 10.1 & 1.01 \\
& Average slope (degrees) & 11.0 & 1.1 \\
Latent susceptibility factors & Distance from fault (m) & 3.4 & 0.34 \\
& Number of potential & 8.3 & 0.83 \\
& streams affected & 12.1 & 1.21 \\
Preservation factors & Geology & 17.2 & 1.72 \\
& Number of erosion ditches & 13.4 & 1.34 \\
& Distance from the collapse (m) & 100 & 10 \\
& Trotal & 59.9 & 5.99 \\
\end{tabular}

In its geological aspects, this research is based on the results of a survey by the Civil Engineering Research Institute of the Ministry of Construction of Japan regarding where earth-rock flows occur, along with the characteristics of Taiwan geology. Adopting a predetermined risk standard of geological lithology, this study divides such geology into three broad categories, based on the maximum, minimum and intermediate values. Among the preservation factors, traffic and farmland were deemed to be either "present" or "not present" and also allocated based on the minimum values.

\section{Discussion}

\subsection{Risk Assessment of River Terraces}

The evaluation results for each river terrace are shown in Table 5. The average value (57.70) and standard deviation (13.346) were calculated by statistical methods, with the average value as the center plus or minus one standard deviation. After adjusting with the concept of rounding to integers, the boundaries were 70,55 and 40. Thus, risk was divided into four categories: high risk (70-100), medium-high risk (55-69), medium risk (41-54) and low risk (0-40). These categories are also presented in map form in Figure 4. 
After the risk assessment, 8 of the 40 focal river terraces were deemed to be high risk, 14 at medium-high risk, another 14 at medium risk, and the remaining 4 at low risk.

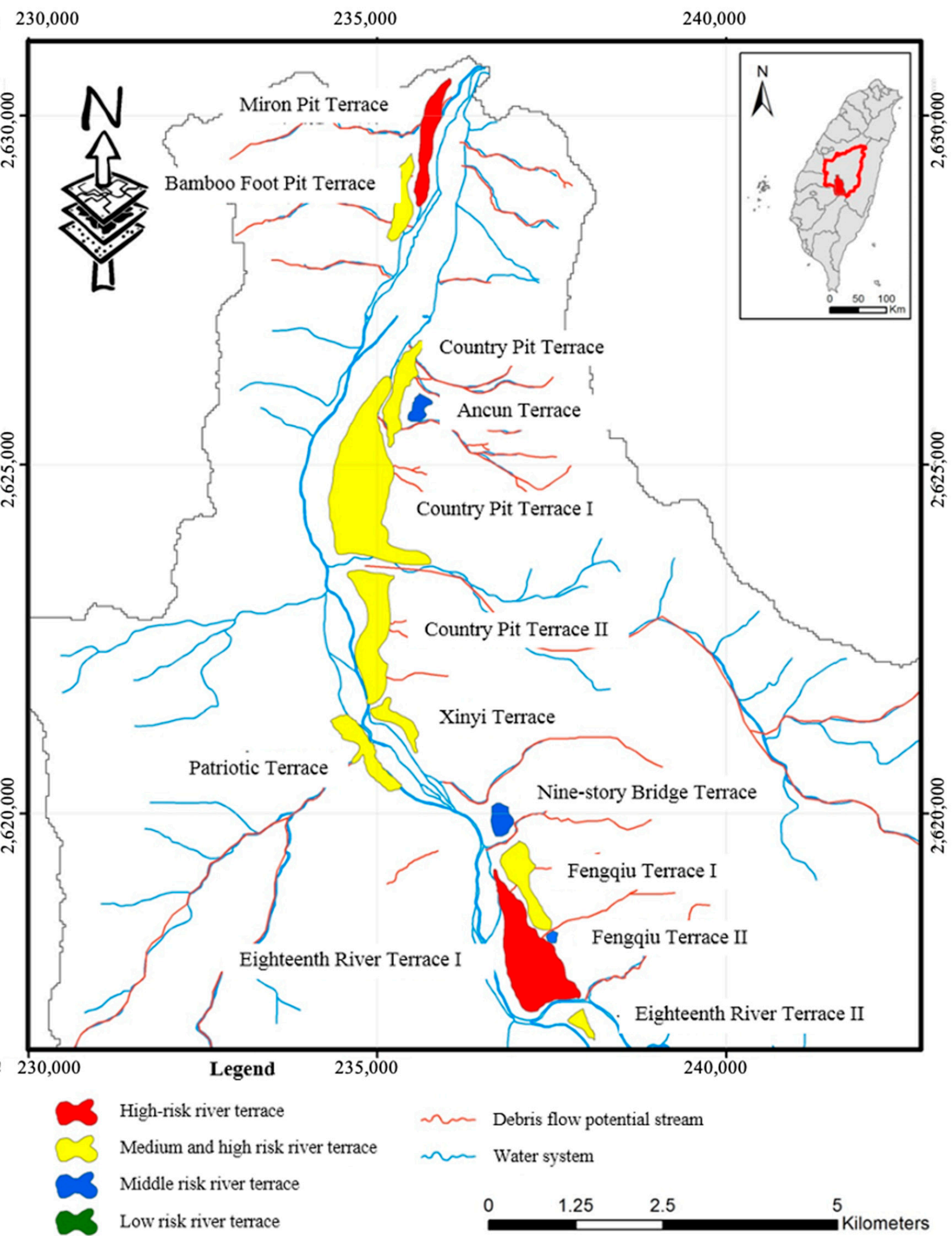

Figure 4. The distribution map of the danger degree of the river terrace. 
Table 5. Risk assessment of river terraces.

\begin{tabular}{|c|c|c|c|}
\hline No. & River Terrace Name & Risk & Hazard Classification \\
\hline 1 & Miron Pit Terrace & 67 & Medium high \\
\hline 2 & Bamboo Foot Pit Terrace & 59 & Medium high \\
\hline 3 & County Pit Terrace & 72 & High \\
\hline 4 & Ancun Terrace & 49 & Medium \\
\hline 5 & County Pit Terrace I & 79 & High \\
\hline 6 & County Pit Terrace II & 85 & High \\
\hline 7 & Xinyi Terrace & 81 & High \\
\hline 8 & Patriotic Terrace & 78 & High \\
\hline 9 & Nine-story Bridge Terrace & 49 & Medium \\
\hline 10 & Fengqiu Terrace I & 66 & Medium high \\
\hline 11 & Eighteenth River Terrace I & 76 & High \\
\hline 12 & Fengqiu Terrace II & 45 & Medium high \\
\hline 13 & Eighteenth River Terrace II & 53 & Medium high \\
\hline 14 & Xinxiang Terrace & 53 & Medium high \\
\hline 15 & Rona Terrace I & 55 & Medium \\
\hline 16 & Rona Terrace II & 70 & High \\
\hline 17 & Trench Terrace & 38 & Low \\
\hline 18 & Ali Does Not Move the River Terrace I & 35 & Low \\
\hline 19 & Ali Does Not Move the River Terrace II & 65 & Medium high \\
\hline 20 & Wangmei Terrace & 50 & Medium \\
\hline 21 & Ali Does Not Move the River Terrace III & 39 & Low \\
\hline 22 & Wangxiang Terrace & 49 & Medium \\
\hline 23 & Ali Does Not Move the River Terrace IV & 68 & Medium high \\
\hline 24 & Heshe Terrace & 78 & High \\
\hline 25 & Malacca Terrace I & 59 & Medium high \\
\hline 26 & Malacca Terrace II & 42 & Medium \\
\hline 27 & Toutunxi Terrace I & 67 & Medium high \\
\hline 28 & Toutunxi Terrace II & 59 & Medium high \\
\hline 29 & Four Districts & 44 & Medium \\
\hline 30 & No. 3 Creek Terrace & 65 & Medium high \\
\hline 31 & Upper Fourth terrace & 37 & Low \\
\hline 32 & No. 4 Creek Terrace & 41 & Medium \\
\hline 33 & Dongpu Bridge Terrace I & 55 & Medium high \\
\hline 34 & Dongpu Bridge Terrace II & 52 & Medium \\
\hline 35 & Dongpu Terrace I & 50 & Medium \\
\hline 36 & Dongpu Terrace II & 62 & Medium high \\
\hline 37 & Dongpu Terrace III & 47 & Medium \\
\hline 38 & Dongpu Terrace IV & 63 & Medium high \\
\hline 39 & Dongpu Terrace V & 57 & Medium high \\
\hline 40 & Ugankeng River Terrace & 49 & Medium \\
\hline
\end{tabular}

\subsection{Verification}

Three comparison methods were used in this research to verify our approach. These were: (1) unsupervised classification using the SPOT-3 satellite multi-spectral state (XS) image map of Chen Youlanxi in each period to determine changes in river-terrace area;

(2) comparison of river terraces in various periods with satellite images and aerial photos;

(3) comparison of historical disaster data from the Chenyulan River, covering a total of 87 floods linked to 42 discrete weather events from August 1959 through October 2009 [43].

\subsection{Historical Disaster Comparison}

\subsubsection{Dangerous River Terraces}

As noted above, eight river terraces were deemed high-risk by our approach because they scored above 70 points. This indicated that the frequency of disasters there is high, damage to buildings and crops is noteworthy, and the area affected is relatively large. From historical disaster data, it can be seen that debris flows struck these eight terraces at 1.36 times the average rate; dike destruction (by number of occurrences) and land loss (in 
hectares) were both 5 times the average; houses totally destroyed, 4.44 times the average; damaged houses, 4.09 times the average; number of deaths, 2.74 times the average.

\subsubsection{County Pit I}

County Pit I is a high-risk river terrace located on the right bank of the lower reaches of Chenyulan River. Figure 5 was obtained by extracting and overlapping images from five periods and shows little change in this area before and after Typhoon Hebo, whereas after Typhoon Tochigi, a shrinking trend in its land area can be observed. After the 72nd flood, the terrace's area was obviously reduced, but after Typhoon Morakot five years later, it had increased.

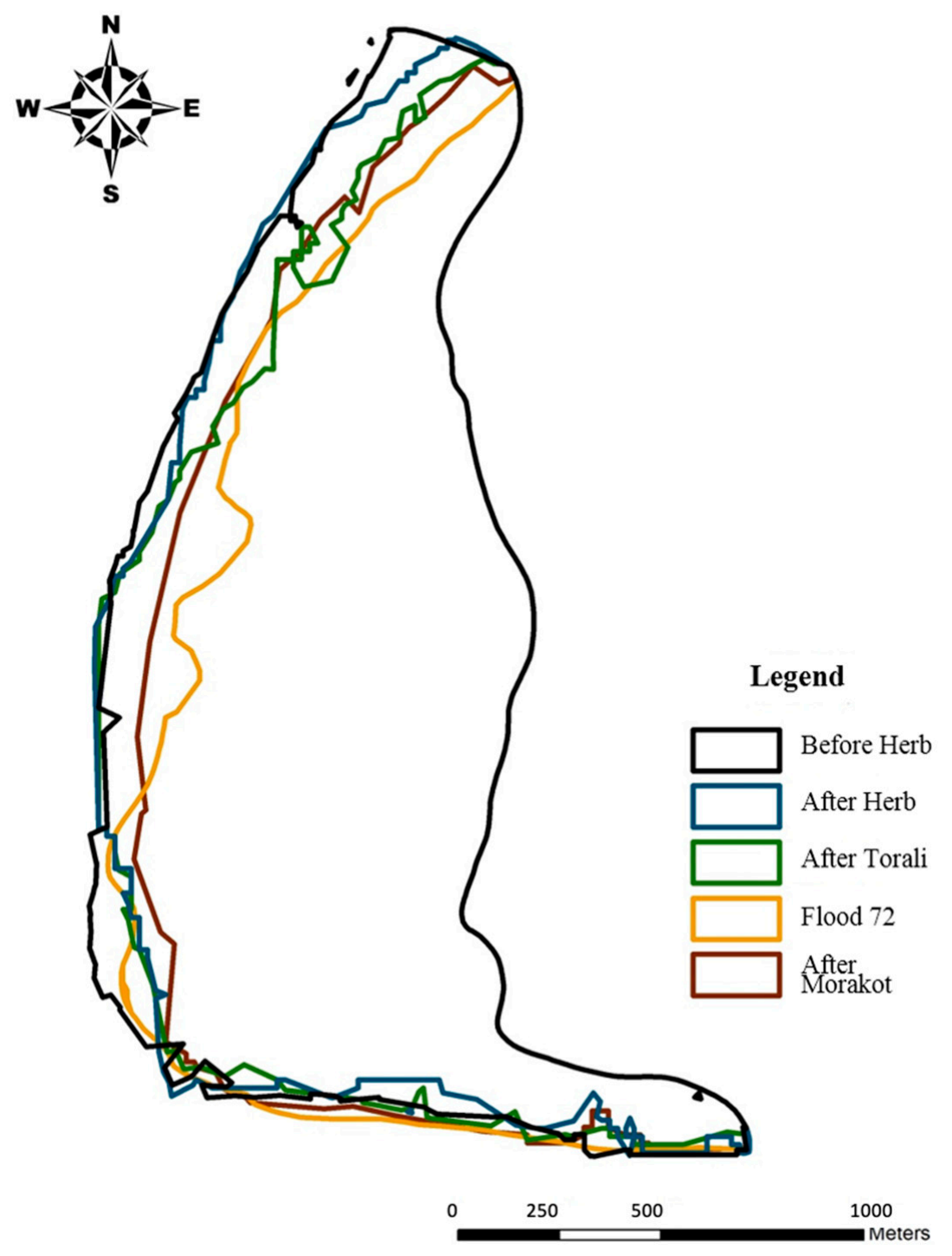

Figure 5. Area changed to County Pit I across five flooding events.

County Pit Terrace I was destroyed by Typhoon Mintouli in 2004, which in turn caused the embankment of Junkengxi Terrace I to be washed away. The disaster area was very large, as shown in aerial photographs obtained from the Fourth River Bureau, Water Resources Department, Ministry of Economic Affairs (Figures 6-9). 


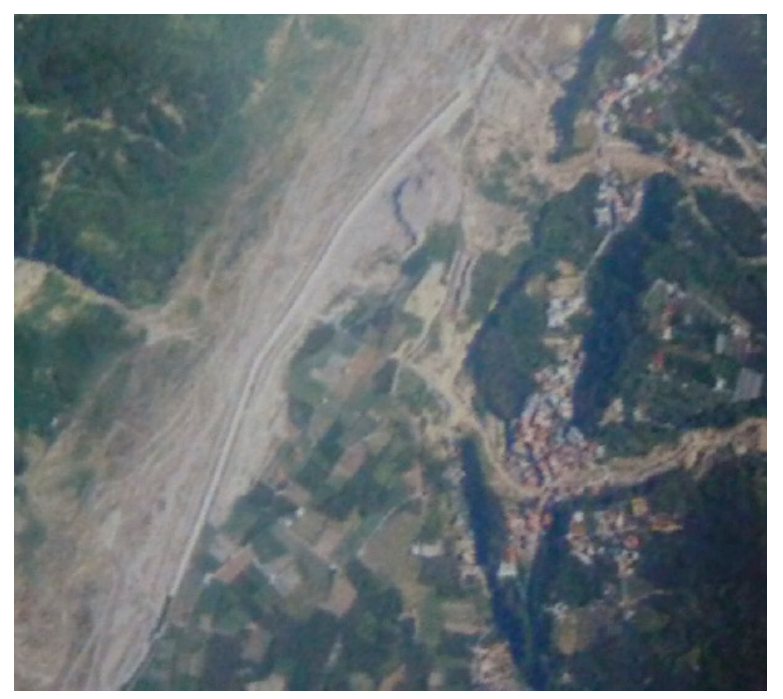

Figure 6. The County Pit embankment in 2003 (the year before it was destroyed).

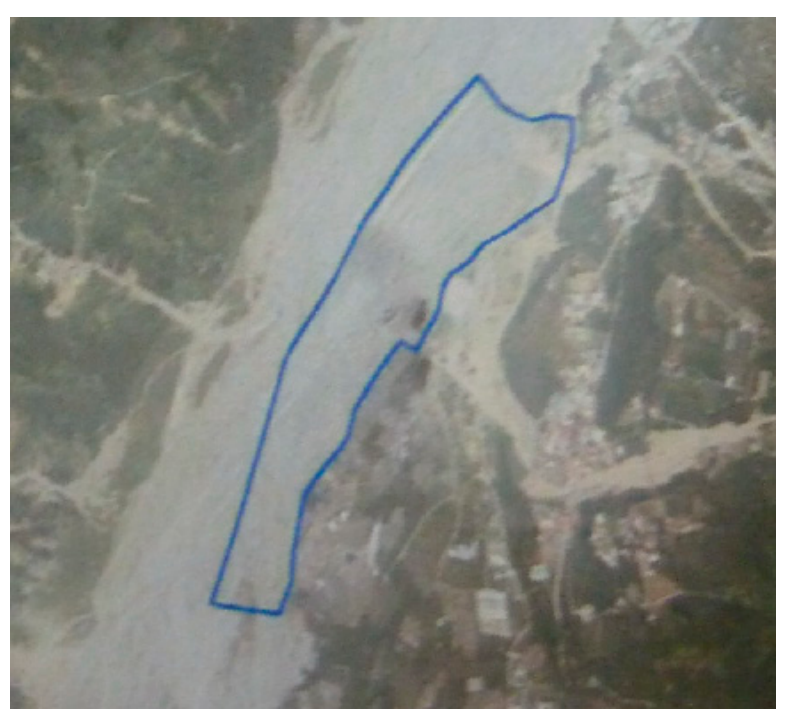

Figure 7. The former area of the County Pit embankment, marked in blue, in 2004.

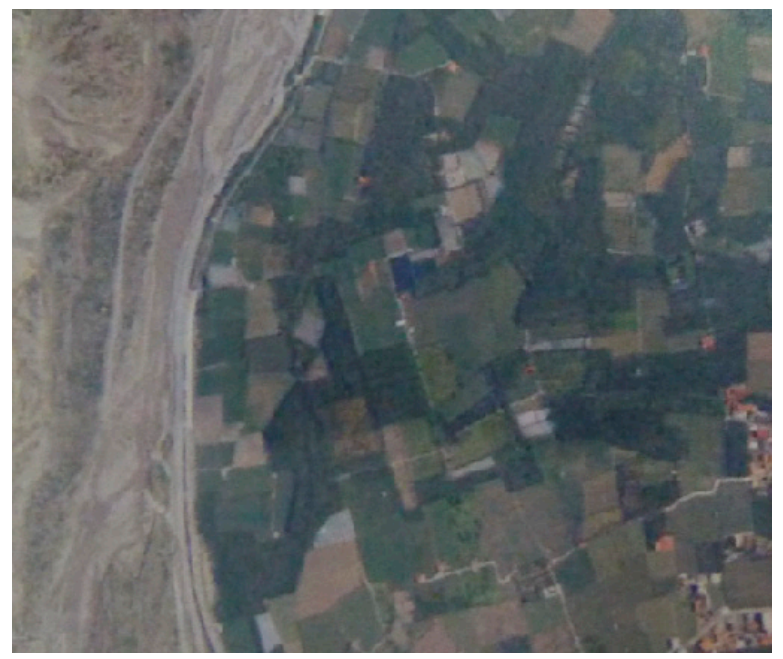

Figure 8. The Shang'an embankment in 2003 (before its destruction). 


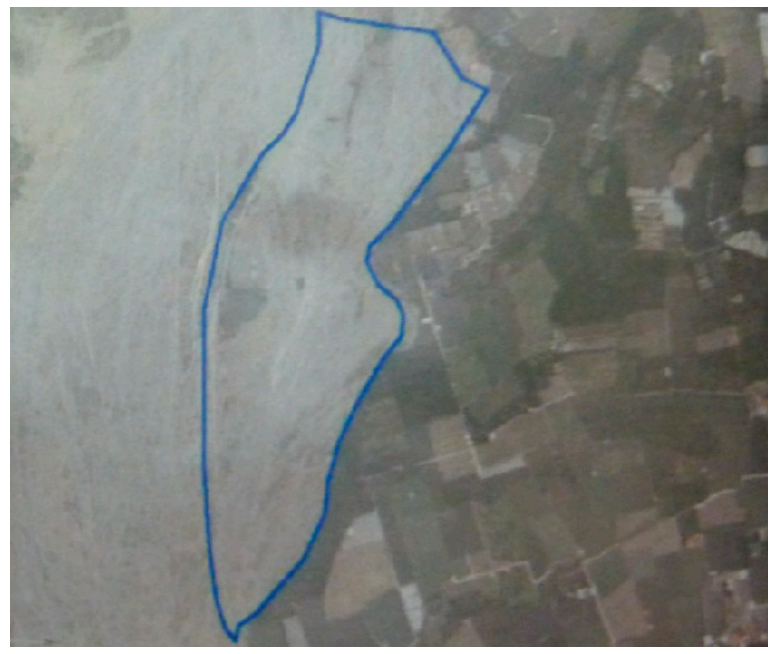

Figure 9. The former area of the Shang'an embankment, marked in blue, in 2004.

\subsubsection{Toutunxi Terrace I}

Toutunxi I is a medium-high-risk river terrace located on the right bank of the middle reaches of Heshe River. A schematic diagram of its changes, based on image extraction and overlap from five flooding events, is presented in Figure 10. It is obvious from Figure 10 that the area of the terrace was broadly unchanged after Typhoon Toraji and the 72nd flood, but after Typhoon Morakot, it was significantly reduced.

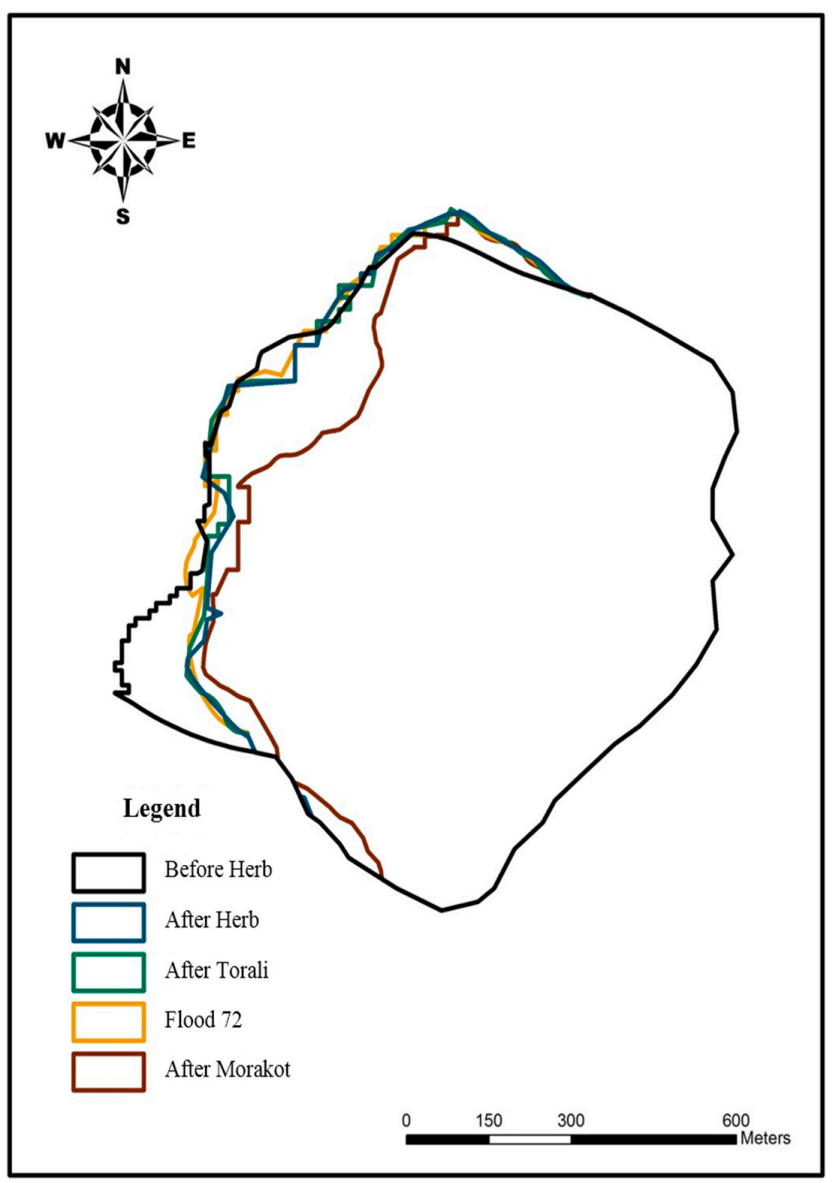

Figure 10. Area changed to Toutunxi Terrace I across five flooding events. 
During Typhoon Morakot in 1998, three large landslides in the upper reaches of Toutunxi Creek indirectly formed soil and rock flows, which caused both banks of the downstream terraces to be washed away. In a satellite image from before this disaster (Figure 11, left), the channel of the Toukeng River is not obvious, being then only 20-30 m wide, but one taken after it (Figure 11, right) shows the channel clearly, as it had widened to $120 \mathrm{~m}$.

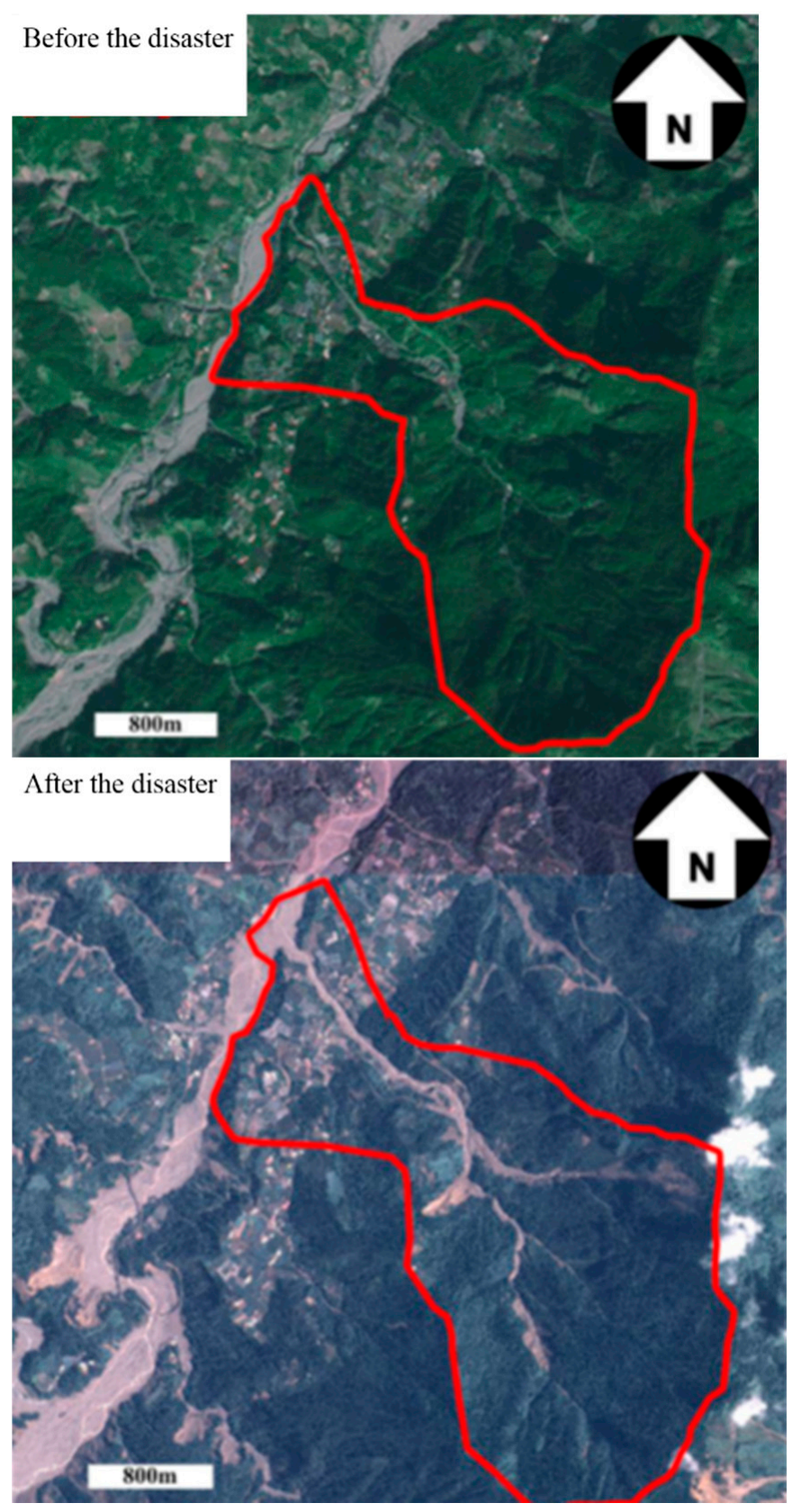

Figure 11. The confluence of Toutunxi Creek and the Toukeng River before and after Typhoon Morakot in 1998, with study area marked in red.

\section{Conclusions}

The latent-susceptibility factors selected in this study through the literature were the length of the attacking bank, distance from fault, distance from river course, number of potential debris flows, minimum specific height, average slope, geology, number of erosion ditches, distance to collapsed land, etc. The three preservation factors selected were the preservation of households, transportation and farmland; the risk to particular river 
terraces was established from the latent-susceptibility factors and preservation factors. The results of the AHP analysis indicated that, among the latent-susceptibility factor conditions, those affecting the front of the river terrace were considered more important than those affecting the river terrace itself or the area behind it. Additionally, the results indicated that the preservation of households was deemed more important than traffic or farmland factors. The research also established that, of the 40 focal river terraces, the highest-risk ones were County Pit Terrace, County Kengxi Terraces I and II, Xinyi Terrace, Patriotic Terrace, Eighteenth Terrace I, Rona Terrace II and Heshe Terrace. In this study, a potential factor assessment framework was established to examine whether the research results were contradictory by comparing SPOT satellite images and historical hazards. Unlike other risk assessments of riverine terraces $[10,11]$, the current environmental conditions of riverine terraces can be used to assess the risk of disasters. This study's risk-level designation has important implications for both disaster prevention and the evacuation of local residents when disasters occur, and, if generally adopted, it should mitigate loss of life and property. However, this study was not without its limitations. Chief among these was that it relied on the $5 \mathrm{~m} \times 5 \mathrm{~m}$ DTM of Taiwan surveyed and mapped by the Chengda Satellite Center in 2004 to conduct its river-terrace risk assessments and stability analyses. The use of a more recent DTM would undoubtedly increase the accuracy of the analysis results. Additionally, when conducting stability analysis, due to limited drilling data from the Chenyulan River Basin, such data from Toutunxi River Terrace I were used as a proxy for it. Thus, more geological data would, therefore, improve our approach's ability to identify potential river-terrace collapses.

Author Contributions: Conceptualization, J.-Y.L.; data curation, Y.-M.H.; writing—original draft, Y.-M.H.; writing - review and editing, J.-C.C.; supervision, J.-Y.L. All authors have read and agreed to the published version of the manuscript.

Funding: This study is part of the research results of the Ministry of Science and Technology number NSC100-2218-E-005-001. I would like to thank the staff for their hard work during the planning period and to express their greatest gratitude to the National Science Council for their support research. Funding has enabled this study to be successfully completed.

Institutional Review Board Statement: Not applicable.

Informed Consent Statement: The authors declare no conflict of interest.

Data Availability Statement: The data presented in this study are available in the article.

Acknowledgments: We would like to thank the anonymous reviewers for their helpful suggestions and feedback.

Conflicts of Interest: The authors declare no conflict of interest.

\section{References}

1. Li, X.D. From the point of view of topography, Chen Youlan's He Bo Feng disaster. Geotech. Technol. 1996, 17-24. Available online: http:/ / www.geotech.org.tw/purchase-inner.php?id=131 (accessed on 15 November 2021).

2. Liu, M.X. Topographical Research on the River Steps in the Northwest of Taiwan. Ph.D. Thesis, Department of Geography, National Taiwan Normal University, Taipei, Taiwan, 2004.

3. Du, H.Y.; Chen, H.H.; Cao, B.X. Geomorphology and Quaternary Geology; one edition of Three Brushes; Geological Publishing House: Beijing, China, 1991.

4. Chang, R.J.; Shi, Z.T. An overview of the study of the rivers. J. Chin. Geogr. Soc. 1990, 18, 1-8.

5. Ger, M.L. A Study of the Relations between the Terraces and Subsurface Structure in the Hsinshe Area. Ph.D. Thesis, Department of Geography, National Taiwan Normal University, Taipei, Taiwan, 2005.

6. Wang, F.T. Comparison of River Terraces in Hua-Tung Coast Area: A Case Study in Streams of Shuilian, Shuimuding and Sanxian. Master's Thesis, Department of History and Geography, University of Taipei, Taipei, Taiwan, 2016.

7. Chang, T.Y. Fluvial Terrace Landscape in Tai-Yuan Basin and Its Implications. Master's Thesis, Department of Natural Resources and Environmental Studies, National Dong Hwa University, Hualien County, Taiwan, 2016.

8. Wu, T.Y. Holocene Landscape Evolution of the Jinlun, Dazhu and Dawu River Basins in the Southeastern Taiwan. Master's Thesis, Department of Geography, National Kaohsiung Normal University, Kaohsiung, Taiwan, 2019. 
9. Chen, Y.C. Application of Geographic Information System in Risk Asssessment of River Terrace in Chenyulan River Watershed, Nantou County. Master's Thesis, Department of Civil and Construction Engineering, Chaoyang University of Technology, Taichung, Taiwan, 2010.

10. Zhuang, Z.Z. Apply Artificial Intelligence and Weight of Evidence to Assess Vulnerability for River Terrace Communities Master's Thesis, Department of Land Management and Development, Chang Jung Christian University, Tainan, Taiwan, 2020.

11. Lin, J.R. Risk Assessment of Rainfall-induced Landslides for River Terrace Communities. Master's Thesis, Department of Land Management and Development, Chang Jung Christian University, Tainan, Taiwan, 2020.

12. Chang, C.F. Effects of Watershed Runoff Factors on Debris Flow Occurrence-Using the Watershed of Chenyoulan Stream as An Example. Master's Thesis, Department of Bioenvironmental Systems Engineering, National Taiwan University, Taipei, Taiwan, 2015.

13. Lin, S.Y. Study on the Factors of Landslide Susceptibility Analysis in Chen- You-Lan Watershed. Master's Thesis, Department of Soil and Water Conservation, National Chung Hsing University, Taichung, Taiwan, 2018.

14. Thi-To, N.N. Early Warning of Landslide Hazard by Integrating Spatial Statistical Analysis Methods to Calculate the Landslide Susceptibility Index in the Chen-Yu-Lan River Watershed. Taiwan. Ph.D. Thesis, Department of Earth Sciences, National Cheng Kung University, Tainan, Taiwan, 2019.

15. Debris Flow Disaster Prevention Information, Soil and Water Conservation Bureau. Available online: https://246.swcb.gov.tw / ?lang=en (accessed on 15 November 2021).

16. Lin, M.L.; Wu, W.L.; Zhou, K.X.; Yang, Z.S.; Wang, J.P. Discussion on Geographical Location Types and Remediation Cases of Taiwan Slope Disasters. CECI Eng. Technol. 2008, 77. Available online: https://www.ceci.org.tw/Upload/Download/F8950026-8 5C8-4386-9075-13CCB737881D.pdf (accessed on 15 November 2021).

17. Lin, D.G.; Lai, Y.C.; Liu, W.T. Design and analysis of natural ecological method for river and stream improvement. In Proceedings of the Natural Ecological Practices Conference, Taitpi, Taiwan, November 2002. Available online: https:/ /www.m.ishare.iask. sina.com.cn/f/34860363.html (accessed on 15 November 2021).

18. Su, K.H. Investigating the Slope Failure of Interbedded Sandstone and Mudstone Slope: Case of Highway R174 on $50 \mathrm{k}+650$. Master's Thesis, Institute of Resources and Environment, University of Kang Ning, Taipei, Taiwan, 2007.

19. Central Weather Bureau. Available online: https://www.cwb.gov.tw/eng/ (accessed on 15 November 2021).

20. Lin, C.W. Geological Factors to Influence the Landslides in The Hoshe Area, Nantou Hsien. Sino-Geotech. 1996, 57, 5-16.

21. Wang, M.H. Application of SPOT Satellite Images and GIS for Landslide Potential Analysis-A Case Study of Shao-Lai River. Master's Thesis, Department of Civil and Construction Engineering, Chaoyang University of Technology, Taichung, Taiwan, 2008.

22. Chu, Y.T.; Hsu, M.L. The Relationship between Discharge and Suspended Sediment Concentration at Typhoon Events in Yu-Feng Catchment. J. Geogr. Sci. 2007, 49, 1-22.

23. Huang, T.H. The Study of Slope Landslide Disaster Management-Take Tainan County for Example. Master's Thesis, Department of Land Management and Development, Chang Jung Christian University, Tainan, Taiwan, 2004.

24. Zhang, L.; Weng, Y.; Chen, X.H. Research on evaluation model for vulnerability of flood control based on SVM. Yangtze River 2009, 40 .

25. Lin, C.K. Topography of Taiwan, Taiwan Provincial General Records 1957, 1. (Land Records, Geography, Volume 1), published by the Taiwan Provincial Literature Committee, 424 pp. Available online: https:/ / tm.ncl.edu.tw /article?u=006_001_0000395034 \&lang=chn (accessed on 15 November 2021).

26. Lin, C.C. Topography of Taiwan, Draft of the General Gazetteer of Taiwan Province, Taiwan Provincial Literature Committee. 1, 1957.

27. Wang, L.C. The Characteristics of Topography and Occurrence of Hillslope Debris Flows in Shitou area. Master's Thesis, Department of Earth Sciences, National Cheng Kung University, Tainan, Taiwan, 2005.

28. Cheng, Y.C. Application of Geographic Information System to Regional Slope Stability Analysis-Tianxiang-Tailuege Section of Zhongheng Highway. Master's Thesis, Department of Materials Science and Engineering, National Cheng Kung University, Tainan, Taiwan, 1992.

29. Kao, C.L. A Study on the Failure Potential of Slopes along 31 75 K Section of the 14th Provential Highway. Master's Thesis, Department of Civil and Construction Engineering, Chaoyang University of Technology, Taichung, Taiwan, 2003.

30. Liu, H.F. Evaluation of Slope Failures along the 14th Provincial Highway Using Artificial Neural Networks. Master's Thesis, Department of Civil and Construction Engineering, Chaoyang University of Technology, Taichung City, Taiwan, 2005.

31. Hou, C.F. Application of SPOT Remote Sensing Images and GIS on Landslide potential Analysis Using Chen Yu Lan Creek Basin. Master's Thesis, Department of Civil and Construction Engineering, Chaoyang University of Technology, Taichung, Taiwan, 2006.

32. Luo, S.Y.; Huang, H.Y. Chenyulan. Available online: http://www1.geo.ntnu.edu.tw/ \{\}shensm/Course/CourseWork/TaiGeom_ Stu90/24.25\%E9\%99\%B3\%E6\%9C\%89\%E8\%98\%AD\%E6\%BA\%AA/ (accessed on 15 November 2021).

33. Jeng, F.S.; Lin, M.L. Engineering Deficiencies Exposed by Typhoon Herb. Sino-Geotech. 1996, 57, 65-74.

34. Chang, W.C. Research on the Sustainability of Debris Flow Influenced Areas in Yilan County with the Application of the Fuzzy Backpropagation Neural Network Deduction Pattern. Master's Thesis, Department of Civil Engineering, National Ilan University, Ilan, Taiwan, 2006.

35. Taiwan's Water Resources Agency, MOEA. Available online: https:/ /eng.wra.gov.tw/ (accessed on 15 November 2021).

36. Chang, S.J. Hillside Survey Planning, Evaluation and Slump Prediction and Management. Master's Thesis, Department of Geography, National Taiwan Normal University, Taibei, Taiwan, 1993. 
37. Hung, J.J. Typhoon Herb, The New-Central-Cross-Island-Highway and Slopeland Failures in Central Taiwan. Sino-Geotechnics 1996, 57, 25-30.

38. Tarng, H.R. The Transportation and Deposition of Catastrophic Landslides in Taiwan: Insight from Granular Discrete Element Simulation. Ph.D. Thesis, Department of Geosciences, National Taiwan University, Taibei, Taiwan, 2010.

39. Chi, C.C. Investigation and Interpretation of Rock Slide Potential. Nation Sci. Technol. Cent. Disaster Reduct. 2010, 62. Available online: https:/ / www.ncdr.nat.gov.tw/Epaper/MessageView?itemid=5061\&mid=39 (accessed on 15 November 2021).

40. Saaty, T.L.; Vargas, T.L. Comparision of igenvalue, logarithmic least squares and least squares medthods in estimationg ratios Mathematic. Modelling 1984, 5, 309-324. [CrossRef]

41. Shrestha, R.K.; Alavalapati, J.R.; Kalmbacher, R.S. Exploring the potential for silvopasture adoption in south-central Florida: An application of SWOT-AHP method. Agric. Syst. 2004, 81, 185-199. [CrossRef]

42. Juang, C.H.; Chen, C.J. A rational method for development of limit state for liquefaction evaluation based on shear wave velocity measurements. Int. J. Numer. Anal. Methods Geomech. 2000, 24, 1-27. [CrossRef]

43. Lai, M.F. Application of GIS to Spatial Characteristic of Rainfall-Chenyulan River Watershed as an Example. Master's Thesis, Department of Civil and Construction Engineering, Chaoyang University of Technology, Taichung, Taiwan, 2010. 